\title{
Anesthetic management of a parturient with carnitine palmitoyltransferase II deficiency
}

\section{[Anesthésie d'une parturiente qui présente un déficit en carnitine palmitoyltrans-} férase II]

Suzanne Lilker MD FRCPC, Shilpa Kasodekar MD, Eric Goldszmidt MD FRCPC

Purpose: To report the anesthetic management of a patient with carnitine palmitoyltransferase II deficiency who presented for labour and delivery.

Clinical features: A 30-yr-old primiparous woman with known carnitine palmitoyltransferase II deficiency and a past history of exercise induced muscle pain, weakness and myoglobinuria presented in active labour. Management consisted of an early epidural for labour and continuous dextrose infusion with frequent blood sugar monitoring. She had an uneventful spontaneous vaginal delivery. She experienced a single asymptomatic episode of hypoglycemia on the first postpartum day. Her serum creatine kinase was six times normal at $24 \mathrm{hr}$ postdelivery and remained elevated for three days without evidence of rhabdomyolysis. The remainder of her postpartum course was uneventful.

Conclusion: Labour and delivery is a potential precipitant of rhabdomyolysis in patients with carnitine palmitoyltransferase II deficiency. The normal postpartum creatine kinase elevation (two to four times baseline at $24 \mathrm{hr}$ ) must be taken into account when monitoring these patients. On the basis of the physiologic principles, institution of early epidural analgesia to blunt the stress response to labour and delivery, continuous dextrose infusion and frequent glucose monitoring during labour and postpartum are the mainstays of management.

Objectif: Présenter l'anesthésie d'une patiente atteinte d'un déficit en carnitine palmitoyltransférase II hospitalisée pour un accouchement.

Éléments cliniques: Une primipare de 30 ans, connue pour un déficit en carnitine palmitoyltransferase II et des douleurs musculaires induites par l'exercice, de la faiblesse et de la myoglobinurie, s'est présentée en travail actif. Une analgésie épidurale précoce pour le travail et une perfusion de dextrose continue sous vérification fréquente des glycémies ont été instituées. L'accouchement $a$ été spontané, par voie vaginale. Elle n'a eu qu'un seul épisode d'hypoglycémie asymptomatique au premier jour du postpartum. La créatine-kinase sérique était six fois plus élevée que la normale à $24 \mathrm{~h}$ après l'accouchement et est demeurée élevée pendant trois jours sans preuve de rhabdomyolyse. Le reste du postpartum a été sans incident.

Conclusion : Le travail et l'accouchement peuvent précipiter une rhabdomyolyse en présence de déficit en carnitine palmitoyltransferase II. L'élévation normale de la créatine-kinase au cours du postpartum (deux à trois fois les mesures de base à $24 \mathrm{~h}$ ) doit être prise en compte pendant le monitorage de ces patientes. Partant des principes physiologiques, l'institution d'une analgésie épidurale précoce, pour réduire la réaction de stress du travail et de l'accouchement, d'une perfusion de dextrose continue et du monitorage fréquent du glucose pendant le travail et le postpartum sont les principales mesures thérapeutiques.

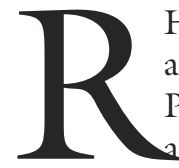
HABDOMYOLYSIS results from damage to the sarcolemma of skeletal muscle. Possible sequelae include: myoglubinuria, acute renal failure, hyperkalemia with cardiac arrest, disseminated intravascular coagulation and compartment syndrome. Although there are many possible etiologies, the most common inherited cause is carnitine palmitoyltransferase (CPT) II deficiency.

In patients with adult CPT II deficiency, attacks of myalgias or even rhabdomyolysis and myoglobinuria have been precipitated by exercise, fasting, infection, cold, emotional stress, drugs such as valproic acid, ibuprofen or high dose diazepam, as well as general anesthesia. ${ }^{1}$ Labour and delivery also have the poten-

From the Department of Anesthesia and Pain Management, Mount Sinai Hospital, University of Toronto, Toronto, Ontario, Canada. Address correspondence to: Dr. Eric Goldszmidt, Mount Sinai Hospital, 600 University Avenue \#1514, Toronto, Ontario M5G 1X5,

Canada. Phone: 416-586-5270; Fax: 416-586-8664; E-mail: e.goldszmidt@utoronto.ca

Funding: All authors supported by departmental funding only.

Accepted for publication October 17, 2005.

Revision accepted December 1, 2005.

Competing interests: None declared. 
TABLE Laboratory test values

\begin{tabular}{|c|c|c|c|c|c|c|c|c|}
\hline Value & Units & Normal range & Admission & Postdelivery & $\begin{array}{l}12 \mathrm{hr} \\
\text { postpartum }\end{array}$ & $\begin{array}{l}24 \mathrm{hr} \\
\text { postpartum }\end{array}$ & $\begin{array}{l}\text { Postpartum } \\
\text { day } 2\end{array}$ & $\begin{array}{l}\text { Postpartum } \\
\text { day } 3\end{array}$ \\
\hline $\mathrm{Hb}$ & $\mathrm{g} \cdot \mathrm{L}^{-1}$ & $110-150$ & 144 & & & & & \\
\hline Plt & $10^{9} \cdot \mathrm{L}$ & $130-400$ & 188 & & & & & \\
\hline Glucose & $\mathrm{mmol} \cdot \mathrm{L}^{-1}$ & $4-8$ & 4.3 & 5.4 & 3.6 & 6.0 & 6.3 & 5.4 \\
\hline $\mathrm{CK}$ & $\mathrm{U} \cdot \mathrm{L}^{-1}$ & $0-190$ & 104 & 167 & 326 & 669 & 512 & 265 \\
\hline CK-MB & $\mu g \cdot \mathrm{L}^{-1}$ & $0-6.5$ & 8.3 & & 13.4 & 22.7 & 19.6 & 9.1 \\
\hline \multicolumn{9}{|l|}{ Mass index } \\
\hline Potassium & $\mathrm{mmol} \cdot \mathrm{L}^{-1}$ & $3.5-5.0$ & 4.7 & & 3.6 & 4 & & \\
\hline Lactate & $\mathrm{mmol} \cdot \mathrm{L}^{-1}$ & $0.5-2.0$ & & & 2.3 & 1.8 & & \\
\hline $\begin{array}{l}\text { Urine } \\
\text { myoglobin }\end{array}$ & & negative & & & & negative & negative & \\
\hline
\end{tabular}

$\mathrm{Hb}=$ hemoglobin; $\mathrm{Plt}=$ platelets $\mathrm{CK}=$ creatine kinase CK-MB = creatine kinase myocardial band.

tial to precipitate rhabdomyolysis in patients with CPT II deficiency. This report describes the management and successful outcome of a parturient with the adult form of this inherited disorder. Informed written consent for the use of personal health information was obtained from the patient in accordance with institutional guidelines.

\section{Case report}

A 30-yr-old primiparous woman of Ashkenazi Jewish descent with known CPT II deficiency presented to the labour and delivery unit in labour at 40 weeks gestation.

Her CPT II deficiency had been diagnosed at age eight when she developed muscle aches after severe exertion and the pediatrician noted myoglobinuria. A subsequent muscle biopsy confirmed the diagnosis of CPT II deficiency. Genetic testing revealed that she had two separate CPT II gene mutations and was heterozygous with haplotypes LIVQ -SVfsM. She was advised to avoid fasting and overexertion and to have frequent high carbohydrate meals. She had experienced several episodes of muscle cramping after sports activity followed by weakness and pigmenturia. She was not hospitalized during these episodes, never developed renal failure, and usually experienced resolution within a week. She had approximately two such episodes per year triggered by exercise, sleep deprivation, fasting and extremes of temperature. Her last episode was one year prior to her becoming pregnant. During pregnancy, she experienced occasional myalgia without pigmenturia, associated with heavy lifting. She experienced no hypoglycemic symptoms. Her sister was affected by the same disorder, but she also had a history of rhabdomyolysis with acute renal failure after running a marathon. She had three pregnancies, which were uneventful.

The patient was seen in both the anesthesia consult clinic and the maternal medicine clinic. She was advised of her risk for developing metabolic disorders such as hypoglycemia, metabolic acidosis and rhabdomyolysis with fasting and the stress of labour. She was advised to eat and drink well, and that a dextrose infusion would be admininstered throughout labour, with institution of an early epidural to reduce the stress and fatigue of labour. The second stage of labour would be shortened, if necessary, using either a vacuum or forceps to reduce maternal expulsive efforts. Blood glucose CK and concentrations were to be followed during the peripartum period.

Upon arrival to the labour floor, the patient had been experiencing mild contractions every $20 \mathrm{~min}$ for about eight hours. Her membranes ruptured one hour prior to admission with a subsequent increase in the intensity and frequency of contractions. She was contracting every two minutes and was found to be $2 \mathrm{~cm}$ dilated and fully effaced. An $18 \mathrm{G}$ iv line was established and an infusion of 10\% dextrose was administered at a rate of $100 \mathrm{~mL} \cdot \mathrm{hr}^{-1}$. Blood glucose concentrations were evaluated every two hours while in labour and postpartum on the delivery unit. An epidural catheter was inserted at the L3-4 interspace one hour after arrival without any difficulty. She received a test dose of $2 \%$ lidocaine $3 \mathrm{~mL}$ followed by a loading dose of bupivacaine $0.125 \% 10 \mathrm{~mL}$ with fentanyl $100 \mu g$. Patient-controlled epidural analgesia with bupivacaine $0.0625 \%$ and fentanyl $2 \mu \mathrm{g} \cdot \mathrm{mL}^{-1}$ (bolus $5 \mathrm{~mL}$, lockout five minutes, infusion $10 \mathrm{~mL} \cdot \mathrm{hr}^{-1}$ and maximum $40 \mathrm{~mL} \cdot \mathrm{hr}^{-1}$ ) was initiated. She had good analgesia with pain scores of less than, or equal to 
$3 / 10$. After four hours she was $5 \mathrm{~cm}$ dilated and had a T4 block with mild motor block (Bromage 1) bilaterally. She had no muscle cramps and her upper extremities were not weak. She felt slight heaviness in the chest, likely related to the T4 block. This was managed expectantly, and sensory analgesia receded to T8 bilaterally within $30 \mathrm{~min}$. Three hours later, she was fully dilated and began pushing. She had a spontaneous vaginal delivery within $40 \mathrm{~min}$ from the start of pushing. The baby weighed $3335 \mathrm{~g}$ with Apgars of 9 and 9 at one and five minutes. She did not complain of muscle cramps or fatigue postdelivery, and her urine remained clear throughout the course of labour and delivery. Peripartum biochemistry values are summarized in the Table. Creatine kinase and blood glucose were normal on admission, and remained so during labour and immediately postpartum.

Seven hours after delivery the patient was transferred to the ward. As soon as she was tolerating oral fluids, the dextrose infusion was discontinued. She was breastfeeding and felt fatigued, but did not experience any muscle cramps. On the morning of the first postpartum day, approximately $12 \mathrm{hr}$ postpartum, she developed mild hypoglycemia and had an elevated CK three times baseline value. Lactic acid was mildly elevated. She was encouraged to eat more frequently, and serum glucose was normal. At $24 \mathrm{hr}$ postpartum she felt less fatigued. The CK concentration had risen to six times baseline, with normal lactic acid. Urinary myoglobin was negative. The CK concentration decreased on the second and third postpartum days, and repeat urinalysis remained negative for myoglobin. She was discharged on the third postpartum day with advice to seek help at home, since sleep deprivation and the stress of caring for the baby in the early postpartum period could theoretically trigger rhabdomyolysis. She remained asymptomatic on subsequent postpartum followup.

\section{Discussion}

The labour, delivery and early postpartum course for this patient with CPT II deficiency were uneventful. She did not develop any symptoms or signs of rhabdomyolysis. Although she had brief hypoglycemia on the first postpartum day, she experienced only mild fatigue. There was an elevation in serum CK at 24 hr postpartum to six times the baseline value. In the normal parturient, $\mathrm{CK}$ is known to increase during labour and reach a peak of two- to fourfold baseline concentrations $24 \mathrm{hr}$ postpartum, then gradually decline. Nulliparous patients can attain higher CK concentrations than multiparous patients. Creatine kinase myocardial band (CK-MB) is also increased. ${ }^{2}$
Carnitine palmitoyltransferase deficiency was first described in 1973 by Di Mauro et al. ${ }^{3}$ It results in a defect of mitochondrial fatty acid oxidation which does not manifest until the patient is fasting and fatty acid oxidation begins to play a role in energy production. Fatty acids are activated to form $\mathrm{CoA}$ thioesters through acyl-CoA synthetases. During fasting, acylCoA esters are channeled to mitochondria for $B$-oxidation. The carnitine cycle is required for mitochondrial entry of long chain fatty acids. ${ }^{4}$ A plasma membrane carnitine transporter maintains the intracellular supply of carnitine. Carnitine palmitoyltransferase I, on the outer mitochondrial membrane, converts acyl-CoA esters to acylcarnitine analogues. Transmembrane transfer of acylcarnitine is mediated by carnitine/acylcarnitine transferase. Carnitine palmitoyltransferase II, on the inner mitochondrial membrane, re-esterifies acylcarnitines to form acyl-CoA esters.

There are three different forms of CPT II deficiency. The adult form usually presents between the ages of 15 and $30 \mathrm{yr}$ with episodes of myalgia, myoglobinuria, and weakness after prolonged exercise, stress and fasting. These patients have elevated creatine kinase $(\mathrm{CK})$ during an exacerbation and may experience fasting ketogenesis and hypoglycemia. Carnitine palmitoyltransferase II deficiency may present with considerable heterogeneity. ${ }^{5}$ There is a fatal neonatal form and a severe infantile form which result in seizures, hypoketotic hypoglycemia, hepatomegaly, cardiomegaly and cardiac arrhythmias.

Intense exercise for more than $40 \mathrm{~min}$ is associated with a transition of muscle metabolism from glucose and glycogen stores to lipid substrate. ${ }^{6}$ In a patient with a disorder of fatty acid oxidation, more glucose and glycogen stores will be used to derive energy in the form of adenosine triphosphate and thus there is a risk of hypoglycemia if additional glucose is not supplied.

Previous case reports and review articles of CPT II deficiency suggest labour and delivery can be safe with iv dextrose supplementation and close monitoring of blood sugars. Most reports also recommend early analgesia. ${ }^{1,6-9}$ The first case report of CPT II deficiency in pregnancy was published in $1994 .^{7}$ It describes the use of a $10 \%$ dextrose infusion and close monitoring of blood sugars in a woman with CPT II deficiency during labour. This patient did not develop rhabdomyolysis after a Cesarean section for failure to progress. There was no discussion of anesthetic management in that case report. Labour analgesia was discussed in another report of a patient with CPT II deficiency and idiopathic thrombocytopenic purpura. ${ }^{6}$ Neuraxial anesthesia was recommended to alleviate 
stress of labour and to prevent rhabdomyolysis associated with CPT deficiency. A single shot spinal was chosen, as she presented late in labour. This patient also received a $10 \%$ dextrose infusion at $50 \mathrm{~mL} \cdot \mathrm{hr}^{-1}$. Her CK was elevated to $405 \mathrm{U} \cdot \mathrm{L}^{-1}$ and the patient developed myoglobinuria, which resolved by the first postpartum day. Another case report of CPT II deficiency during labour, proposes that neuraxial anesthesia and glucose infusion are optimal management to avoid rhabdomyolysis. ${ }^{8}$ Combined spinal-epidural analgesia was chosen for labour analgesia to minimize motor block. Labour pain evokes a generalized neuroendocrine stress response that has widespread physiological effects on the parturient and fetus. ${ }^{10}$ The sequelae of hyperventilation, secretion of stress related hormones and increased oxygen consumption can be prevented, obtunded or abolished by central neuraxial blockade. It is on this basis that early epidural analgesia is recommended in CPT deficiency.

Special attention must be given to patients with CPT deficiency who undergo general anesthesia. Multiple cases of intra and postoperative rhabdomyolysis and renal failure have been reported in patients who have received volatile anesthetics and succinylcholine. ${ }^{11-13}$ Some of these reactions may be similar in clinical presentation to malignant hyperthermia reactions. It is unclear whether direct effects of the anesthetic medications, the stress of surgery, or perioperative fasting are the key precipitating factors. While CPT deficiency does not predispose patients to malignant hyperthermia, it is unclear whether a trigger-free anesthetic will lessen their risks of such an event.

These patients should have an antepartum anesthesia consult to discuss early epidural analgesia and to formulate an intrapartum management plan. On admission, patients should receive an infusion of $10 \%$ dextrose at a rate of 1 to $1.5 \mathrm{~mL} \cdot \mathrm{kg}^{-1} \cdot \mathrm{hr}^{-1}$. Dextrose should be continued into the postpartum period until the patient is eating well. Blood glucose should be monitored every two hours during labour and every two to four hours postpartum for $24 \mathrm{hr}$. In our case, the patient developed mild hypoglycemia $18 \mathrm{hr}$ after delivery. A baseline CK level should also be established, and repeated postpartum, as CK levels usually peak around $24 \mathrm{hr}$ postdelivery. Subsequent sampling should be done to verify that $\mathrm{CK}$ levels are falling appropriately. Interpretation of $\mathrm{CK}$ and $\mathrm{CK}-\mathrm{MB}$ results must take into account the normal elevation after labour and delivery. If there is clinical evidence of rhabdomyolysis such as muscle cramps, weakness and fatigue, or dark urine, more frequent bloodwork and urine testing for myoglobin is recommended. If CK is elevated more than usual, or if urine myoglobin is positive, renal function, electrolytes and coagulation should be evaluated, and urine output carefully followed.

Carnitine palmitoyltransferase II deficiency should be considered in the differential diagnosis of any patient who develops postpartum muscle aches, weakness and myoglobinuria. Labour and delivery is a potential precipitant of rhabdomyolysis in patients with CPT II deficiency. On the basis of the physiologic principles, institution of early epidural analgesia to blunt the stress response to labour and delivery, continuous dextrose infusion and frequent glucose monitoring during labour and postpartum are the mainstays of management for the prevention of rhabdomyolysis.

\section{References}

1 Deschauer M, Wieser T, Zierz S. Muscle carnitine palmitoyltransferase II deficiency: clinical and molecular genetic features and diagnostic aspects. Ach Neurol 2005; 62: 37-41.

2 Abramov $\Upsilon$, Abramov D, Abrahamov A, Durst R, Schenker J. Elevation of serum creatine phosphokinase and its MB isoenzyme during normal labor and early puerperium. Acta Obstet Gynecol Scand 1996; 75 : 255-60.

3 Di Mauro S, Di Mauro PM. Muscle carnitine palmityltransferase deficiency and myoglobinuria. Science 1973; 182: 929-31.

4 Roe CR, Coates PM. Mitochondrial fatty acid oxidation disorders. In: Scriver CR, Beaudet AL, Sly WS, Valle D (Eds). The Metabolic and Molecular Basis of Inherited Disease, 7th ed. New York: McGraw-Hill; 2002: 1501-11.

5 Vladutiu GD, Bennett MJ, Fisher NM, et al. Phenotypic variability among first-degree relatives with carnitine palmitoyltransferase II deficiency. Muscle Nerve 2002; 26: 492-8.

6 Mardirosoff C, Dumont L, Cobin L, Massaut J. Labor analgesia in a patient with carnitine palmityl transferase deficiency and idiopathic thrombocytopenic purpura. Int J Obstet Anesth 1997; 7: 134-6.

7 Dreval, D, Bernstein D, Zakut, H. Carnitine palmitoyl transferase deficiency in pregnancy - a case report. Am J Obstet Gynecol 1994; 170: 1390-2.

8 Moundras JM, Wattrisse G, Leroy B, Decocq J, KrivosicHorber $R$. Prise en charge anesthésique du travail obstétrical chez une parturiente atteinte d'un déficit musculaire en canitine palmitoyl transférase. Ann Fr Anesth Reanim 2000; 19: 611-6.

9 Sigauke, E, Rakheja D, Kitson K, Bennet MJ. Carnitine palmitoyltransferase II deficiency: a clinical, biochemical, and molecular review. Lab Invest 2003; 83: 1543-54. 
10 Brownridge $P$. The nature and consequences of childbirth pain. Eur J Obstet Gynecol Reprod Biol 1995; 59(Suppl): S9-15.

11 Katsuya H, Misumi M, Obtani $\Upsilon$, Miike T.

Postanesthetic acute renal failure due to carnitine palmityl transferase deficiency. Anesthesiology 1988; 68: 945-8.

12 Vladutiu GD, Taggart RT, Smail D, Lindsley HB, Hogan K. A carnitine palmitoyl transferase II (CPT2) Arg503Cys mutation confers malignant hyperthermia and variable myopathy. Am J Hum Genet 1998; 63(Suppl): A5 (abstract).

13 Vladutiu GD, Bennett MJ, Smail D, Wong LJ, Taggart RT, Lindsley HB. A variable myopathy associated with heterozygosity for the R503C mutation in the carnitine palmitoylatransferase II gene. Mol Genet Metab 2000; 70: 134-41. 